\title{
Awareness and characteristics of the mothers of malnourished children under 5 years old on south Tarawa, Kiribati in 2016: a descriptive study
}

\begin{abstract}
Introduction: Childhood malnutrition is the primary cause of death in approximately $35 \%$ of all deaths among children under the age of 5years. Considering the fact that the number of malnutrition cases from 2010 to 2014 in Kiribati ranged from $8.6 \%$ to $20 \%$, mother mothers are the primary caretakers to these vulnerable and innocent children. As there is no any study till now, this descriptive study is conducted to determine the awareness and characteristics of the mothers of malnourished children under 5years old on South Tarawa, Kiribati in 2016.
\end{abstract}

Methodology: This quantitative cross-sectional study is conducted among 82 women with children under 5years old who were identified as being malnourished in 11 public health clinics. A purposive sampling was used to achieve the participants for this study. A self-administrated questionnaire was used to collect the data. Those who met the study inclusion and exclusion criteria were invited to fill the questionnaire. Participants were informed about the aim and the procedure of the study using an information sheet. This data was exported to SPSS Version 22 for data cleaning and analysis.

Results: Two thirds of the women in the study were between 19-32years of age and about half of them pointed that their household's population was highest among 5-8people. Participating mothers had low knowledge about breastfeeding, complementary feeding, dietary practice and immunization. About half of the mothers were not aware that the appropriate time to start complementary feeding is after 6 months old. 22(26.8\%) of the respondents stated they knew that a balanced diet was eating body building, energy and protective foods. Almost $80 \%$ of the mothers thought that a child between 2 to 4years old should have more serves of protective foods in their meals. About (71\%) of the mothers did not know that the use of BCG injection given to a child during birth is to protect against tuberculosis.

Conclusion: This study highlighted the importance of mother awareness on children malnutrition in Kiribati. Health promotion should be reinforced at child welfare clinics, health facilities and at community level to improve parents' knowledge of the recommended infant and child feeding practices.

Keywords: awareness, mothers, malnutrition, under five years old children, kiribati
Volume 6 Issue I - 2017

\author{
Antje Reiher,' Masoud Mohammadnezhad ${ }^{2}$ \\ 'Master of Public Health, Ministry of Health and Medical \\ Services, Kiribati \\ ${ }^{2}$ Associate Professor in Public Health (Health Promotion), \\ School of Public Health and Primary care, Fiji National \\ University, Fiji
}

Correspondence: Masoud Mohammadnezhad, 2Associate Professor in Public Health (Health Promotion), School of Public Health and Primary care, Fiji National University, Fiji

Tel +679-9726I27, Email masraqo@hotmail.com

Received: July 01, 2017 | Published: September 19, 2017

\section{Introduction}

Malnutrition continues to be a significant risk factor for death among children under 5years old, in both developed and developing countries. $^{1}$ The World Food Programme (WFP) reported that malnutrition undernutrition can result from a lack of macronutrients such as carbohydrates, protein and fat and micronutrients lacking vitamins and minerals or it can be both. ${ }^{2}$ Malnutrition in every form presents major threats to human health. Nowadays the world faces a double burden of malnutrition, both undernutrition and overnutrition. In 2010, approximately 104million children globally were underweight and about 43 million children under 5years were overweight. ${ }^{3}$ Present evidence shows that undernutrition is the underlying cause of death in an estimated $45 \%$ of all deaths among children under 5 years of age. ${ }^{4}$ According to the WHO report, it was estimated that 165 million children had stunted growth, 101 million were underweight while 52 million children were wasted; from those figures, Africa contributed to 56 million stunted children and 13.4 million were wasted. ${ }^{5}$ As stated by Black et al., ${ }^{4}$ a severely stunted child faces a 4 times higher risk of dying, while a severely wasted child has a 9 times higher risk. ${ }^{6}$

Chronic malnutrition is still a serious public health problem in many Pacific island countries, with the rates above 40 per cent of the cut off. ${ }^{7}$ Malnutrition amongst children under 5year old is a major public health issue, particularly on the main island of South Tarawa in the Republic of Kiribati. Children represent almost half of the entire population at $42 \%$ and child malnutrition is a serious concern with nearly $15 \%$ of the children underweight and with considerable gaps in immunization. For example, only $29 \%$ of one year old children have received all basic vaccinations and $8 \%$ of one year old have not had any vaccinations at all. ${ }^{8}$ Mother's knowledge is important as the child's care is mostly the responsibility of the mother. As a result, mother's knowledge about the child care has a great impact on the nature and quality of care that is offered to the child. ${ }^{9}$ Due to lack 
of study till now, this descriptive study is aimed to understand the awareness and characteristics of the mothers of malnourished children under 5 years old on South Tarawa, Kiribati.

\section{Methodology}

This cross-sectional study was conducted on South Tarawa, an urban area in Kiribati, at 11 different public health clinics for eight weeks from the $21^{\text {st }}$ of December 2015 to the $12^{\text {th }}$ of February 2016. The inclusion criteria were all women with children under 5 years old who were identified as being malnourished by doctors in the hospital and nurses in the public health clinic, and they were admitted to the Pediatric ward within the period of 1 st January to $31^{\text {st }}$ May 2015. Furthermore, the study participants must be self-identified as I-Kiribati people and their children's names were registered under the public health clinics. Those who were not willing to participate in the study and mothers or children who were not residents on South Tarawa were excluded. A purposive sampling was used to achieve the participants for this study. In total, there were 120 malnourished children under 5years old registered from the Pediatric ward and public health clinics, however, only 82 participants were available. A self-administered questionnaire, based on the literature review and other questionnaires which have been used in previous similar studies to gather data, was used. In total 12 questions were used to measure the participants' awareness including questions on the 4 contributing factors (breastfeeding, complementary feeding, dietary practice and immunization).

On assessment, modified Bloom's cut off points were used where a score of $80-100 \%$ of correct responses meant a good knowledge, a score of $50-79 \%$ was a level of satisfactory knowledge and a poor knowledge was for the respondents with a score less than $50 \%$ of the correct responses..$^{10}$ Prior to collecting the data, the questionnaire was validated using ten participants who met the inclusion criteria and were given the questionnaire to ensure the questions are understandable and readable for face validity. Content validity was done by 3 academic experts for their opinions and feedback to confirm the validity of the questionnaires. Prior to data collection, approval was obtained from the School of Population Health Research Committee, the College of Medicine, Nursing and Health Sciences Health Research and Ethics Committee (CHREC), and from the Ministry of Health in Kiribati. For data analysis, descriptive analysis was used to determine the frequency of responses and displayed in tables by percentage distribution.

\section{Results}

Two thirds of the women in the study were between 19-32years of age $(32.9 \%$ were $19-25$ years old and a further $32.9 \%$ were $26-32$ years old). With respect to their education level, most of mothers had attended high school 55(67.1\%). 38(46.3\%) of the household's population was highest among 5-8 people. Moreover, 26(31.7\%) of mothers had only 1 child (Table 1 ). The majority of mothers knew that exclusive breastfeeding needs to be started from birth till 6months old, while most of the mothers knew that they need to regularly breastfeed their child during illness, 68(82.9\%) and 70(85.4\%), respectively. Most of the mothers $46(56.1 \%)$ were aware that the appropriate time to start complementary feeding is after 6months old while a few, $5(6.1 \%)$, indicated that a good time to start giving complementary food was from 1 to 3 months old. Nearly $82 \%$ of the mothers knew that protective foods should be given to a child when they start eating at 6 months old. On the other hand, $22(26.8 \%)$ of the respondents stated they knew that a balanced diet was eating body building, energy and protective foods, while a good percentage of the respondents, $50(61.0 \%)$, stated that a balanced diet was giving protective foods alone. Almost $80 \%$ of the mothers thought that a child between 2 to 4 years old should have more serves of protective foods in their meals, however, $9(11 \%)$ of the mothers thought that energy foods and body building foods should have more serves in each meal.

About two-thirds (67.1\%) of the participants knew that immunizations are important because they help to prevent disease, and $70(85.4 \%)$ knew that immunization should be started at birth. The majority of the mothers had poor knowledge about immunization. About $(71 \%)$ of the mothers did not know that the use of BCG injection given to a child during birth is to protect against tuberculosis. Along with $72(87.8 \%$ ) not knowing what the 2 doses of immunization were given to their child during birth. Nearly $88 \%$ of the participating mothers were unaware that Hepatitis B should be given within 24hours after birth, and 78(95.1\%) do not know the contents of the pentavalent injection given to their child during immunizations (Table 2).

Table I Demographic status of respondent

\begin{tabular}{|c|c|c|}
\hline Variables & Frequency & Percentage \\
\hline \multicolumn{3}{|l|}{ Age } \\
\hline$<18 \mathrm{yrs}$ & 2 & 2.4 \\
\hline $19-25 y r s$ & 27 & 32.9 \\
\hline $26-32 y r s$ & 27 & 32.9 \\
\hline $33-39 y r s$ & 19 & 23.2 \\
\hline$>40+\mathrm{yrs}$ & 7 & 8.5 \\
\hline \multicolumn{3}{|l|}{ Education Level } \\
\hline Graduate school & 2 & 2.4 \\
\hline High school & 55 & 67.1 \\
\hline Primary school & 24 & 29.3 \\
\hline No education & 1 & 1.2 \\
\hline \multicolumn{3}{|l|}{ Marital Status } \\
\hline Married & 70 & 85.4 \\
\hline Divorced & 1 & 1.2 \\
\hline Separated & 1 & 1.2 \\
\hline Single & 6 & 7.3 \\
\hline Widowed & 4 & 4.9 \\
\hline \multicolumn{3}{|c|}{ Household Population } \\
\hline$<4 \mathrm{ppl}$ & 6 & 7.3 \\
\hline $5-8 \mathrm{ppl}$ & 38 & 46.3 \\
\hline $9-12 \mathrm{ppl}$ & 24 & 29.3 \\
\hline $13+\mathrm{ppl}$ & 14 & 17.1 \\
\hline \multicolumn{3}{|c|}{ Number of Children } \\
\hline 1 & 26 & 31.7 \\
\hline 2 & 17 & 20.7 \\
\hline 3 & 13 & 15.9 \\
\hline 4 & 9 & 11 \\
\hline $5>$ & 17 & 20.7 \\
\hline
\end{tabular}


Table 2 Frequency of responses on Knowledge-related questions

\begin{tabular}{|c|c|c|c|}
\hline Questions & Responses & $\mathbf{N}$ & $\%$ \\
\hline \multirow{3}{*}{ Exclusive breastfeeding is starting from } & Birth till 1-2mth & 8 & 9.8 \\
\hline & $3-5 \mathrm{mth}$ & 6 & 7.3 \\
\hline & Birth till 6mth & 68 & 82.9 \\
\hline \multirow{3}{*}{$\begin{array}{l}\text { When your child is sick do you need to } \\
\text { breastfeed? }\end{array}$} & Regularly & 70 & 85.4 \\
\hline & Sometimes & 11 & 13.4 \\
\hline & Stop breastfeed & 1 & 1.2 \\
\hline \multirow{4}{*}{$\begin{array}{l}\text { What is the appropriate time to start } \\
\text { weaning your child? }\end{array}$} & From 1-3mth & 5 & 6.1 \\
\hline & From 4-6mth & 6 & 7.3 \\
\hline & After 6mth & 46 & 56.1 \\
\hline & From $1+\mathrm{yrs}$ & 25 & 30.5 \\
\hline \multirow{5}{*}{$\begin{array}{l}\text { What type of food should you give your } \\
\text { child when started eating? }\end{array}$} & body building \& protective & 2 & 2.4 \\
\hline & body building \& energy & 1 & 1.2 \\
\hline & body building food & 2 & 2.4 \\
\hline & energy food & 10 & 12.2 \\
\hline & protective food & 67 & 81.7 \\
\hline \multirow{6}{*}{$\begin{array}{l}\text { What is the balance diet that should be } \\
\text { given to a child? }\end{array}$} & energy \& body building food & 1 & 1.2 \\
\hline & energy food & 1 & 1.2 \\
\hline & $\begin{array}{l}\text { energy, protective \& body building } \\
\text { food }\end{array}$ & 22 & 26.8 \\
\hline & protective food & 50 & 61 \\
\hline & protective with body building food & 6 & 7.3 \\
\hline & Others & 2 & 2.4 \\
\hline \multirow{4}{*}{$\begin{array}{l}\text { What type of food does your child ( } 2 \text { - } \\
4 \text { yrs) should have more served of it during } \\
\text { meal? }\end{array}$} & body building food & 9 & 11 \\
\hline & energy food & 9 & 11 \\
\hline & protective food & 64 & 78 \\
\hline & Prevent disease & 55 & 67.1 \\
\hline \multirow{3}{*}{ Why immunization is important? } & Cure disease & 11 & 13.4 \\
\hline & Both & 12 & 14.6 \\
\hline & Don't know & 4 & 4.9 \\
\hline \multirow{3}{*}{$\begin{array}{l}\text { At what age is immunization need to be } \\
\text { started? }\end{array}$} & At birth & 70 & 85.4 \\
\hline & At 6weeks & 4 & 4.9 \\
\hline & Don't know & 8 & 9.8 \\
\hline \multirow{4}{*}{$\begin{array}{l}\text { What is BCG (injection at the shoulder) } \\
\text { protecting your child against? }\end{array}$} & Coughing & 1 & 1.2 \\
\hline & Tuberculosis & 21 & 25.6 \\
\hline & Mumps \& Rubella & 2 & 2.4 \\
\hline & Don't know & 58 & 70.7 \\
\hline \multirow{5}{*}{$\begin{array}{l}\text { At birth your child should be given } 2 \\
\text { doses of injections. }\end{array}$} & Hepatitis/Vit K & 5 & 6.1 \\
\hline & DPT/Hep B & 0 & 0 \\
\hline & Hep B/BCG & 5 & 6.1 \\
\hline & Hep B/Polio & 0 & 0 \\
\hline & Don't know & 72 & 87.8 \\
\hline \multirow{4}{*}{$\begin{array}{l}\text { The first dose of Hep B should be given } \\
\text { within, how many hours? }\end{array}$} & Within 2-3 days & 0 & 0 \\
\hline & within the first $24 \mathrm{hrs}$ after birth & 10 & 12.2 \\
\hline & Within $4-5$ days & 0 & 0 \\
\hline & Don't know & 72 & 87.8 \\
\hline \multirow{4}{*}{$\begin{array}{l}\text { Pentavalent vaccine is a combination of } 5 \\
\text { vaccines in one. What are they? }\end{array}$} & $\begin{array}{l}\text { diptheria,tetanus, whooping cough,Hep } \\
\text { B \& hamophilus influenza type B }\end{array}$ & 2 & 2.4 \\
\hline & $\begin{array}{l}\text { Tuberculosis, diptheria, tetanus, } \\
\text { whooping cough, hepatitis B }\end{array}$ & 2 & 2.4 \\
\hline & $\begin{array}{l}\text { Rubella, tetanus, whooping cough, } \\
\text { hepatitis B and Haemophilus influenza } \\
\text { type b }\end{array}$ & 0 & 0 \\
\hline & Don’t know & 78 & 95.1 \\
\hline
\end{tabular}




\section{Discussion}

Overall, the participating mothers had low knowledge about breastfeeding, complementary feeding, dietary practice and immunization. In the study, most of the mothers were ignorant on what a balanced diet is that should be given to their child. Many of the mothers $50(61 \%)$ stated that protective food alone is a balanced diet. This shows that mothers are not giving the right types of food or a healthy diet to their children in their daily meals. In contrast, a different study was conducted among 597 mothers in Ethiopia to assess the knowledge, attitude and practice of mothers feeding of their under 5 children. When mothers were asked if they knew about a balanced diet for their child, $95.6 \%$ of mothers knew. ${ }^{11}$ A balanced diet is needed in the first 2years of a child's life for growth, development and it improves cognitive development. ${ }^{12}$ In addition to diet, mothers did not understand that a child of 2 to 4years should eat more portions of energy foods in their diet compared to body building and protective foods. As recommended by WHO, energy intake should be in balance with energy spending. ${ }^{13}$ Evidence shows that total fat should not exceed $30 \%$ of total energy intake to avoid unhealthy weight gain. ${ }^{14}$ Because children at that age are so active, energy food will keep them active all day. This could indicate that mothers are not fully aware of what a healthy choice of food is to give to their children. Mothers need to be made aware of the proper quality and quantity of foods to be given to their young children. The nutritional status of children is highly dependent upon how well mothers successfully feed their children with adequate and well balanced nutrition. ${ }^{15}$

In the present study, mothers are also not sure of the right age to start weaning off the breast. These findings are similar to Mohammed, Ghazawy, \& Hassan' study (2014), in their study on weaning knowledge, which stated that $42.6 \%$ of mothers were unaware of the suitable age to start weaning. Almost half $(50.2 \%)$ of the mothers reported that babies should be weaned completely from breast milk at the age of 2 years and $37.1 \%$ said it should be after 1 and half years old. ${ }^{16}$ The type and timing of weaning foods introduced in an infant's diet have a great impact on the child's nutritional status. ${ }^{17}$ The right age and timing for weaning is vital, as stated by Gupta et al., that a child will be put at great risk of malnutrition and illness if the foods are introduced much before or too much after the child reaches 6 months old. ${ }^{18}$

In relation to immunization in our study, most of the mothers do not know the importance of receiving vaccinations for their children. They had limited knowledge on the content of Pentavalent vaccine, which is a new combined vaccine for children. Ninety-five point one percent of the mothers answered that they did not know the contents of the vaccine and more than two thirds, 50(70.7\%), of the participants reported that they do not know the importance of BCG immunization given to their children. All mothers were unable to name all the diseases prevented by DPT vaccines. In a similar study by Achappa, ${ }^{19}$ done on 200 mothers from rural and urban areas, stated that $60.8 \%$ of urban and $84.1 \%$ of mothers in rural areas did not know that tuberculosis is prevented by BCG vaccine. ${ }^{19}$ It is confirmed in another study by Hamid, ${ }^{12}$ that many of the mothers did not know that tuberculosis is prevented by BCG vaccines. ${ }^{20}$ In contrast to Tagbo et al., ${ }^{21}$ mothers had a good knowledge of child immunization. They knew that children need to be immunized and $89.9 \%$ knew the contents of the vaccines are substances that prevent the killer diseases.
The majority of mothers $(80.9 \%)$ stated that they will continue with immunization even though the child suffered an adverse effect. ${ }^{21}$

Low level of knowledge among mothers in this study confirms that mothers need educational intervention to be able to understand the importance of immunization and to be self-motivated to attend to their child immunization clinic at the correct times and not to miss it. Health workers should give a clear explanation to mothers prior to discharging and give them appointment cards so that they will not forget the date of the next appointment. In this study, most of the mothers $(87.8 \%)$ were unaware of the proper time to start the Hepatitis B vaccination and the 2 doses that should be given after birth. Even though mothers had limited knowledge on immunization, all participants' immunized their children, with the majority of mothers completing their immunization record on schedule. Finding the mother's knowledge and practice did not work well in the study, which may have happened because public health nurses are doing all the follow up at the homes of children that did not turn up for immunization, as all the names of children were recorded and updated with their address at the clinic. Therefore, it is hard to miss injections unless they have transferred to a new place and those nurses did not know about them.

The level of mothers' knowledge might be affected by the socioeconomic status of the individual including their education level, if there is a breadwinner at home and employment status. According to this study, the highest percentages of mothers were high school mothers, but most were unemployed. However, health workers should consider that lack of awareness is not the only barrier; habit, sociocultural constraints, and social norms make it difficult to change. ${ }^{22}$ During child health care clinics, health professionals should conduct health awareness to enhance mother's knowledge on a healthy, balanced diet through different stages in the child's life. Demonstrate to mothers how to make healthy and simple foods for their children and also provide a pamphlet to guide them so they can try to practice it at home. According to Briscoe et al., ${ }^{23}$ it was indicated in their study that in order to change the practice of mothers or caregivers, an active learning approach is considered for the implication that a trained worker needs to demonstrate and caregivers need to practice. This strategy is more effective than reading information alone. ${ }^{23}$

\section{Acknowledgements}

None.

\section{Conflict of interest}

The author declares no conflict of interest.

\section{References}

1. Müller O, Krawinkel M. Malnutrition and health in developing countries. CMAJ. 2005;173(3):279-286.

2. Mothers and Young Children. USA: World Food Programme; 2016.

3. Nutrition. Switzerland: WHO; 2016.

4. Black RE, Victora CG, Walker SP, et al. Maternal and child undernutrition and overweight in low-income and middle-income countries. The lancet. 2013;382(9890):427-451.

5. Levels \& Trend in Child Malnutrition. Switzerland: WHO; 2012. p. 1-35. 
6. Black RE, Allen LH, Bhutta ZA, et al. Maternal and child undernutrition: global and regional exposures and health consequences. The lancet. 2008;371(9608):243-260.

7. Ninth Meeting of Ministers of Health for the Pacific Island Countries Honiara, Solomon Islands, 28 June-1 July 2011: report. Swizterland: WHO Regional Office for the Western Pacific; 2011.

8. Kiribati Demographic and Health Survey. USA: Kiribati National Statistics Office; 2009.

9. Kamau-Thuita F, Omwega AM, Muita JW. Child care practices and nutritional status of children aged 0-2 years in Thika, Kenya. East Afr Med J. 2002;79(10):524-529.

10. John J. The knowledge, attitude, practice and perceived barriers towards screening for premalignant cervical lesions among women aged 18year and above, in Songea urban, Ruvuma. USA: Muhimbili University of Health and Allied Sciences; 2011. p. 1-87.

11. Hussien M, Merga B. The assessment of knowledge, attitude and practice (KAP) of mothers in feeding their under five children in rural community of Kellech Tikka Kebele, Sebeta Awas, special zone surrounding Finfinne, Oromia Region. USA: Ababa University; 2014. p. 1-94.

12. Kudlová E, Schneidrová D. Dietary patterns and their changes in early childhood. Cent Eur J Public Health. 2012;20(2):126-134.

13. Ovaskainen ML, Reinivuo H, Tapanainen H, et al. Snacks as an element of energy intake and food consumption. Eur J Clin Nutr. 2006;60(4):494 501

14. Hooper L, Abdelhamid A, Moore HJ, et al. Effect of reducing total fat intake on body weight: systematic review and meta-analysis of randomised controlled trials and cohort studies. BMJ. 2012;345:e7666.

15. Patrick H, Nicklas TA. A review of family and social determinants of children's eating patterns and diet quality. J Am Coll Nutr. 2005;24(2):8392 .
16. Mohammed ES, Ghazawy ER, Hassan EE. Knowledge, attitude, and practices of breastfeeding and weaning among mothers of children up to 2 years Old in a rural area in El-minia governorate, Egypt. J Family Med Prim Care. 2014;3(2):136-140.

17. Choudhari S. Weaning and supplementary practices impressions from a rural community. Indian Journal of Maternal and Child Health. $2012 ; 14(1): 1-9$

18. Gupta R, Gupta R, Mahajan S. Etiological factors of malnutrition among infants of migrant labour population. Indian journal of maternal \& child health. 2010. p. 1-5.

19. Mahalingam S, Soori A, Ram P, et al. Knowledge, attitude and perceptions of mothers with children under five years of age about vaccination in Mangalore, India. Asian Journal of Medical Sciences. 2014;5(4):52-57.

20. Hamid S. Immunization of children in a rural area of North Kashmir, India: A KAP Study. Online Journal of Health and Allied Sciences. 2012;11(1):1-

21. Tagbo B, Uleanya N, Omotowo I. Mothers' knowledge and perception of adverse events following immunization in Enugu, South-East, Nigeria. $J$ Vaccines Vaccin. 2013;4:202.

22. Affleck W, Pelto G. Caregivers' responses to an intervention to improve young child feeding behaviors in rural Bangladesh: a mixed method study of the facilitators and barriers to change. Soc Sci Med. 2012;75(4):651658.

23. Briscoe C, Aboud F. Behaviour change communication targeting four health behaviours in developing countries: a review of change techniques. Soc Sci Med. 2012;75(4):612-621. 